ORIGINAL ARTICLE

\title{
Placental Elasticity (KPA) Assessment by Shearwave Elastography in early detection of Hypotrophic Fetuses
}

\author{
SABAR BUTT ${ }^{1}$, SYED AMIR GILANI ${ }^{2}$, ASIF HANIF ${ }^{3}$, SYEDA KHADIJA-TUL-SUGHRA MURRIUM ${ }^{4}$, AIMA GILANI ${ }^{5}$, RAHAM \\ BACHA $^{6}$, AMJAD IQBAL 7 \\ ${ }^{1}$ Sabari ultrasound training institute Faisalabad , Pakistan. \\ ${ }^{2}$ Dean FAHS, University of Lahore \\ ${ }^{3}$ Associate professor, University of Lahore \\ ${ }^{4,7}$ Assistant professor Department UIRSMIT (FAHS) \\ ${ }^{5} \mathrm{MBBS}$ \\ ${ }^{6}$ Head of Department (UIRSMIT) FAHS, University of Lahore \\ Correspondence to Dr. Sabar Butt Email: arsamali@hotmail.com, Tel: +92300660115,3456489675 and Prof. Syed Amir Gilani Email: \\ profgilani@gmail.com
}

\begin{abstract}
Aim: To see the predictability of the shear wave elastography assessment of placental elasticity (kpa) for early detection of hypotrophic fetuses

Design: Cross sectional comparative.300 single tone pregnancies previously diagnosed as normal and hypotrophic fetuses were included, the placental elasicity assessed by shear wave elastography of both groups and compared.

Methods: We took biometric measurements and Doppler indicis of the uterine, umbilical, and middle cerebral arteries in both groups and screened them for grayscale and colour doppler ultrasonography. The placental elasticity was measured by Shear wave elastography in these groups. The comparison of strain ratios between these groups were done. Statistical analysis was carried out using the Mann-Whitney test. By plotting ROC curves, cut-off values for elasticity were analysed. On Shear wave elastography measurements, the sensitivity and specificity and diagnostic accuracy of hypotrophic fetuses were planned and developed.

Results: The mean placental elasticity in hypotrophic fetuses and normal group was $28.71 \pm 7.28$ and $5.64 \pm 1.53$ respectively while the median placental elasticity in IUGR group was $27 \pm 7$ and $5.50 \pm 2$ with statistically higher median in hypotrophic groups, $\mathrm{p}$-value $<0.001$.

Conclusion: In hypotrophic fetuses, as placental stiff ness values are much higher, therefore for early detection of compromised hypotrophic fetuses, as a non-invasive, supplementary tool to gray-scale and Doppler, the Shearwave elastography can be used.

Keywords: Hypotrophic fetuses, Shear-wave elastography, Placental Elasticity (kpa), IUGR, Uterine artery, Umbilical artery, Middle cerebral artery, resistive index, pulsatility index,
\end{abstract}

\section{INTRODUCTION}

A recently established ultrasound imaging technology is Elastography, the basic notion is to apply internal or external dynamic or static excitation to any tissue to cause it to respond to movement, velocity, or strain, among other things ${ }^{1}$. Shear-wave elastography is based on the hypothesis of induction of mechanical vibrations that create transverse shear waves that spread laterally inside the tissue. By measuring the propagation speed, highly reproducible quantitative data is given. Faster shear wave velocities indicate increased stiffness ${ }^{2}$.

This method determines the target tissue's shear wave velocity (SWV). In other words, an acoustic radiation force's impulse causes negligible tissue displacement. A lateral shear wave propagates the tissue after the distortion is corrected. The SWV can be used to examine tissue elasticity because it is linked to Young's modulus, which is an elasticity metric. Increased SWV is linked to stiffer tissues, and vice versa ${ }^{3}$.

Elastography has been used in clinical practise to assess liver fibrosis, lymph nodes, breast, and thyroid gland abnormalities. In research examining the placenta in

Received on 02-02-2021

Accepted on 12-06-2021 preeclampsia, the quantity of in-vivo elastography, gestational diabetes mellitus, and foetal anomalies that identified increased elasticity values in placentas impacted by these illnesses is limited ${ }^{4}$.

An in-vivo measurement of placental elasticity values in IUGR pregnancies is necessary to better understand the relevance of elastography in IUGR pregnancies in clinical settings. We used shear-wave elastography to assess placental elasticity in IUGR and normal foetuses from 24 to 36 weeks of gestation and compared elasticity values to normal gestational elasticity values to make shear wave elastography a part of the timely recognition of hypotrophic fetuses. Preeclampsia is a common cause of maternal and perinatal morbidity and mortality, with preterm delivery accounting for $5 \%-8 \%$ of all pregnancies and perinatal mortality accounting for $1 \%-3 \%$ of all pregnancies globally ${ }^{5}$.

Disseminated coagulopathy/HELLP syndrome, pulmonary edoema, acute renal failure, placenta abruption, and long-term cardiovascular problems are also symptoms of severe preeclampsia and may cause maternal complications. Fetal problems include foetal growth limitation, preterm birth, and perinatal mortality. This kinetic technique, in contrast to static elastography, provides realtime quantitative data with great reproducibility and no compression effects/artifacts, as well as a deeper tissue 
reaction ${ }^{7}$.An abnormal fetal growth and development, identified as fetal weight below the 10th percentile (or below 2 SD) than the average for gestational age, is fetal growth restriction (early - hypoplastic and late hypotrophic). $2500 \mathrm{~g}$ Cutoff weight is $2500 \mathrm{~g} \mathrm{(5} \mathrm{lb} 80 \mathrm{oz})^{8}$.

Hypotrophic fetuses noticed after 28 weeks. It is the second leading cause of perinatal mortality after prematurity $41 \%{ }^{9}$. Complications such as stillbirths, birth hypoxia, hypothermia, and hypoglycemia, pulmonary hemorrhages, necrotizing enterocolitis, impaired neurodevelopment and inadequate cerebral function in childhood are faced by the fetuses with growth restriction. As adults, they are at increased risk of heart diseases, hypertension and type II diabetes ${ }^{10}$.

Every year out of 30 million infants with fetal growth restriction, $75 \%$ are born in Asia, mainly in South Central Asia. Where $30 \%$ of African children are underweight, the corresponding figure for South Asia is over $50 \%$. In a communal-based study in Karachi, it was clear that among 738 singleton births, the incidence of fetal growth restriction was $24.4 \%$. In Pakistan, the prevalence of IUGR is $25 \%{ }^{11}$.

The occurrence of IUGR may be at any time afterwards 20 weeks of gestation. At the onset of preeclampsia, the severity of foetal insufficiency is primarily determined by the gestational age. Preeclampsia that develops before 34 weeks is frequently related with aberrant Doppler uterine artery results, foetal development limitation, and negative maternal and newborn outcomes. To improve maternal and neonatal outcomes, early patient recording is essential for monitoring and preventative care $^{12}$

The indication of using uterine artery Doppler as part of the usual sonographic screening was derived from the fact of insufficient uteroplacental perfusion in preeclampsia $^{13}$

The presence of bilateral uterine artery notching and elevated uterine artery pulsatility index values were found to be useful in predicting preeclampsia in the second trimester. The research that looked into the uterine artery's prognostic accuracy were made public. Uterine artery Doppler indices have low positive predictive values ${ }^{14}$. The sensitivity of Doppler measurements for detecting preeclampsia was modestly improved by combining the pulsatility index with the best biomarkers. The elasticity imaging approach can be used to directly or indirectly assess tissue elastic modulus ${ }^{15}$.

The goal of this study was to see if shear wave elastography could be used to detect hypotrophic foetuses in a single step, rather than using typical ultrasonographic criteria such foetal biometry and multiple Doppler indices..

\section{MATERIAL AND METHODS}

The study was conducted at sabiry color Doppler ultrasound centre, Faisalabad, Pakistan, after institutional ethical committee approval. Obstetric sonography, Doppler sonography, and The shear wave-elastographic approach was used to perform elastography on an Aplio 500 platinum (CANON MEDICAL SYSTEMS) machine.After taking informed written consent form, data was collected by the researcher through developed structured questionnaire. A single radiologist with 20 years of experience in sonography performed Doppler sonography and elastography in the same session.. The patient lying in the supine position was screened for elastography. In order to achieve a perpendicular image of the closest area of the placenta, Sagittal imaging planes were used. The imaging plane was confined to shallow vision and the imaging focus was elevated over the placenta in both grayscale and elastography imaging to avoid deeper beam penetration over the foetus. Excessive transmission gel was employed to remove any compression artefacts from the probe. During acquisitions, patients were instructed to breathe lightly and not to move. The computer programme displays elastograms in dual mode (vertical/horizontal) simultaneously with grayscale photographs as an overlay to aid morphological correlation of the placenta. A rectangular adjustable inner image box, which comes with the device software, was employed for the SWE test. This inner box depicts the real-time stiffness on a chromatic scale ranging from blue to red, which represents the elastic stiffness (stiffness). The spectral scale's higher threshold can be manually adjusted, however the estimated shear intensity value will not be impacted. The spectral colorcoding box on the image allows you to place the region of interest $(\mathrm{ROI})$ in the area with the most stiffness. After freezing the elastography image, the application allows the operator to place a circular ROI with multiple diameters within the elastography window. Color-saturated photographs were utilised to do computations. The ROI sizes in this study were all fixed to around $5 \mathrm{~mm}$ in all situations. Tissue elasticity was measured in kilopascals $(\mathrm{kPa})$ on the continuum scale, which led to the ROI cursor positioning. The US picture window was narrowed to provide appropriate image quality and more accurate elasticity measurements. After the display image was frozen, the ROI was used to quantify the minimum, maximum, and mean elasticity of four samples from different placental areas. The following variables were used to obtain data for the Questionnaire's variables,sonographic gestational age, uterine artery pusatility index (PI) \& resistive index $(\mathrm{RI})$, umbilical artery resistive index $(\mathrm{RI})$ \& systolic/diastolic ratio (SD ratio), Middle cerebral artery pusatility index $(\mathrm{PI})$ \& resistive index (RI), intra uterine growth restriction (IUGR) and placental elasticity. Patients with obstetric illnesses other than preeclampsia were also excluded from the study, including anencephalia, hydrops fetalis, Chiari malformations, diabetes, and polyhydramnios with band formation, oligohydramnios, and bronchopulmonary sequestration. Because the detection depth of the ultrasonography probes was $8 \mathrm{~cm}$, patients with a placenta in a posterior position were also excluded.

\section{RESULTS}

There was a positive significant association between placental elasticity and uterine artery $\mathrm{RI}$ in both the IUGR and normal groups, with $r=0.549, p$-value 0.001 and $r=$ $0.0246, p$-value $=0.002$ respectively. Placental elasticity and uterine artery $\mathrm{PI}$ had a positive significant connection in both the IUGR and normal groups, with $r=0.287, p$ value 0.001 and $r=0.031$, $p$-value 0.001 and $r=0.031$, $p$ value 0.001 and $r=0.031, p$-value 0.001 and $r=0.031, p$ value 0.001 and $r=0.031$, In IUGR group there was 
negative significant correlation between placental elasticity and umbilical artery SD i.e. $r=-0.69$, $p$-value $\leq 0.001$ while in normal group there was no significant correlation between placental elasticity and umbilical artery SD i.e. $r=0.0027, p-$ value $=0.740$. In IUGR group there was positive significant correlation between placental elasticity and umbilical artery PI i.e. $r=0.491, p$-value $=0.030$ while in normal group there was no significant correlation between placental elasticity and umbilical artery PI i.e. $r=-0.032$, $p$-value $=0.70$. In IUGR group there was no significant correlation between placental elasticity and middle cerebral RI i.e. $r=-0.002, p-$ value $=0.977$ while there was negative significant correlation between placental elasticity and middle cerebral RI i.e. $r=-0-172, p$-value $=0.035$. In IUGR and normal group there was no significant correlation between placental elasticity and middle cerebral PI i.e. $r=-0.080, p-$ value $=0.331$ and $r=-0.128, p$-value $=0.120$ respectively.

According to receiver operative characteristics cure (ROC) the best predictor of IUGR was placental elasticity (kpa) with area under curve $=1, p$-value $<0.001$, uterine artery $\mathrm{RI}$ with area under curve $=1$, p-value $<0.001$, preceding by uterine artery $\mathrm{PI}$ with area under curve $=0.993$ , p-value $<0.001$, umbilical artery $\mathrm{PI}$ with area under curve $=0.909, p$-value $<0.001$ and umbilical artery SD with area under curve $=0.761, p$-value $<0.001$. The lowest predictors of IUGR was middle cerebral PI with area under curve = 0.129 , $p$-value $<0.001$ and middle cerebral $\mathrm{Rl}$ with area under curve $=0.008, p$-value $<0.001$. According to receiver operative characteristics cure (ROC) the best predictor of IUGR was placental elasticity (kpa) with area under curve $=1$, $p$-value $<0.001$, uterine artery $\mathrm{RI}$ with area under curve $=1$, p-value $<0.001$, preceding by uterine artery $\mathrm{PI}$ with area under curve $=0.993$, p-value $<0.001$, umbilical artery $\mathrm{PI}$ with area under curve $=0.909, \mathrm{p}$-value $<0.001$ and umbilical artery SD with area under curve $=0.761, p$-value $<0.001$. The lowest predictors of IUGR was middle cerebral $\mathrm{PI}$ with area under curve $=0.129, \mathrm{p}$-value $<0.001$ and middle cerebral $\mathrm{RI}$ with area under curve $=0.008, \mathrm{p}$-value $<0.001$.

Fig.1: Area under curve for different parameters for prediction of IUGR

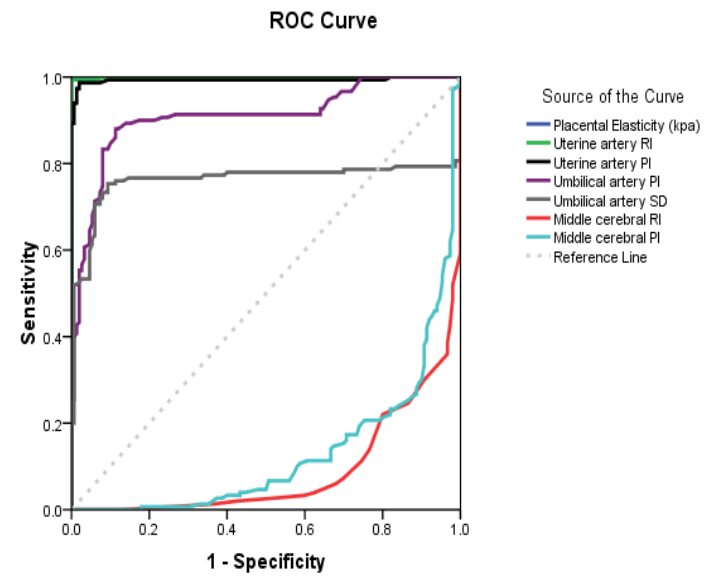

Diagonal segments are produced by ties.
Table 1: Correlation between uterine artery (RI, PI), Umbilical artery $(\mathrm{SD}, \mathrm{Pl})$ and middle cerebral $(\mathrm{RI}, \mathrm{PI})$

\begin{tabular}{|c|c|c|}
\hline & & Placental Elasticity (kpa) \\
\hline \multirow{2}{*}{ Uterine artery $\mathrm{RI}$} & IUGR & $r=0.549 p$-value $<0.001^{\star *}$ \\
\hline & Normal & $r=0.0246, p$-value $<0.002^{* \star}$ \\
\hline \multirow{2}{*}{ Uterine artery $\mathrm{PI}$} & IUGR & $r=0.287, p$-value $<0.001^{* *}$ \\
\hline & Normal & $r=0.0310, p$-value $<0.001^{* *}$ \\
\hline \multirow{2}{*}{$\begin{array}{l}\text { Umbilical artery } \\
\text { SD }\end{array}$} & IUGR & $r=-0.690, p$-value $<0.001^{* *}$ \\
\hline & Normal & $r=0.0027, p$-value $=0.740$ \\
\hline \multirow{2}{*}{$\begin{array}{l}\text { Umbilical artery } \\
\mathrm{PI}\end{array}$} & IUGR & $\mathrm{r}=0.491, \mathrm{p}$-value $<0.001^{* *}$ \\
\hline & Normal & $r=-0.032, p$-value $=0.700$ \\
\hline \multirow{2}{*}{$\begin{array}{ll}\text { Middle } & \text { cerebral } \\
\mathrm{RI} & \\
\end{array}$} & IUGR & $r=-0.002, p$-value $=0.977$ \\
\hline & Normal & $r=-0.0172, p$-value $=0.035^{*}$ \\
\hline \multirow{2}{*}{$\begin{array}{ll}\text { Middle } & \text { cerebral } \\
\text { PI } & \\
\end{array}$} & IUGR & $r=-0.080, p$-value $=0.331$ \\
\hline & Normal & $r=-0.128, p$-value $=0.120$ \\
\hline
\end{tabular}

${ }^{* *}$ Highly Significan , ${ }^{\star}$ Significant

Table 2: Area Under the Curve for different parameters to predict IUGR

\begin{tabular}{|c|c|c|c|c|}
\hline \multirow{2}{*}{$\begin{array}{l}\text { Test } \\
\text { Variable(s) }\end{array}$} & \multirow[b]{2}{*}{ Area } & \multirow[b]{2}{*}{$P$ value } & \multicolumn{2}{|c|}{ Asymptotic $95 \%$ C.I } \\
\hline & & & $\begin{array}{l}\text { Lower } \\
\text { Bound }\end{array}$ & $\begin{array}{l}\text { Upper } \\
\text { Bound }\end{array}$ \\
\hline $\begin{array}{l}\text { Placental Elasticity } \\
\text { (kpa) }\end{array}$ & 1.000 & $<0.001$ & 1.000 & 1.000 \\
\hline Uterine artery RI & 1.000 & $<0.001$ & .998 & 1.001 \\
\hline Uterine artery PI & .993 & $<0.001$ & .982 & 1.004 \\
\hline Umbilical artery PI & .909 & $<0.001$ & .874 & .944 \\
\hline Umbilical artery SD & .761 & $<0.001$ & .696 & .826 \\
\hline Middle cerebral PI & .129 & $<0.001$ & .089 & .169 \\
\hline Middle cerebral RI & .088 & $<0.001$ & .057 & .119 \\
\hline
\end{tabular}

a. Null hypothesis: true area $=0.5$

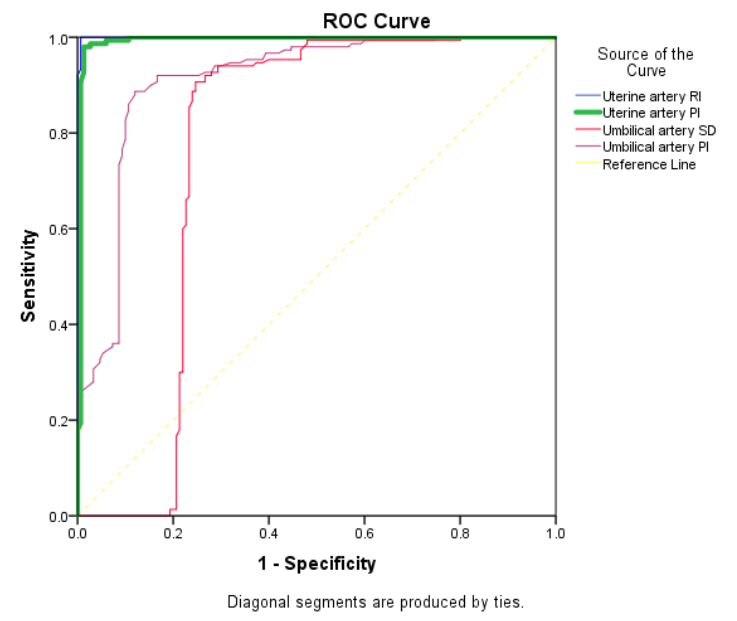

\begin{tabular}{|c|c|}
\hline \multicolumn{2}{|l|}{ Area Under the Curve } \\
\hline Test Result Variable(s) & Area \\
\hline Uterine artery RI & 1.000 \\
\hline Uterine artery $\mathrm{PI}$ & .993 \\
\hline Umbilical artery SD & .761 \\
\hline Umbilical artery PI & .909 \\
\hline $\begin{array}{l}\text { The test result variable } \\
\text { Umbilical artery SD, U } \\
\text { between the positive ac } \\
\text { state group. }\end{array}$ & $\begin{array}{l}\text { tery } \mathrm{RI} \text {, Uterine artery } \mathrm{Pl} \text {, } \\
\mathrm{AP} \text { has at least one tie } \\
\mathrm{up} \text { and the negative actual }\end{array}$ \\
\hline
\end{tabular}




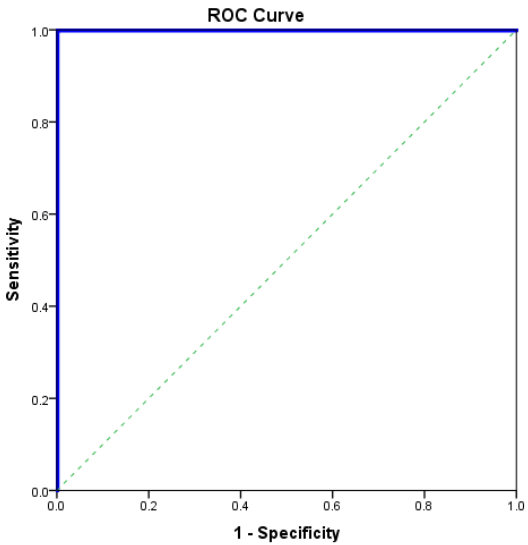

Area Under the Curve

Test Result Variable(s): Placental Elasticity (kpa)

Area

1.000

At $15 \mathrm{Kpa}$, sensitivity is $100 \%$ and specificity is $100 \%$.

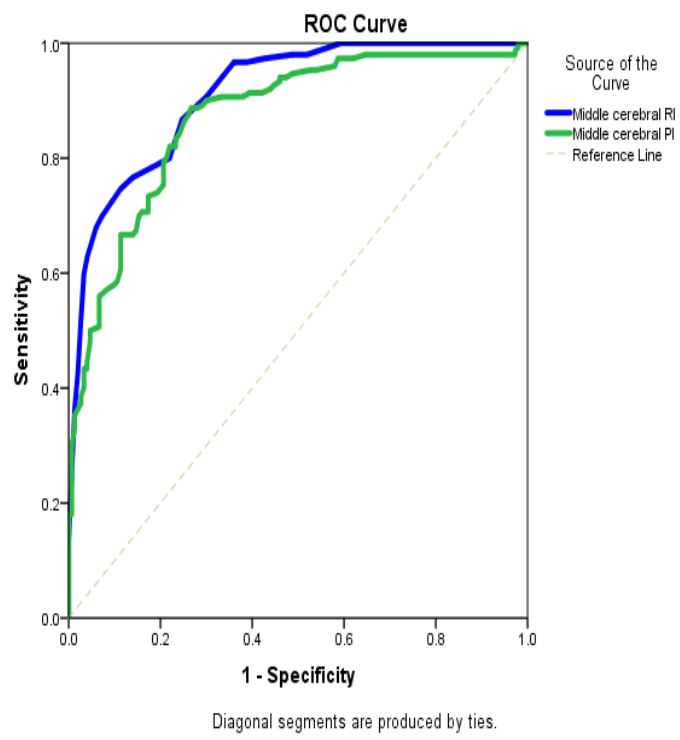

\begin{tabular}{|ll|}
\hline Area Under the Curve & \\
\hline \hline Test Result Variable(s) & Area \\
\hline Middle cerebral RI & .912 \\
\hline Middle cerebral PI & .871 \\
\hline
\end{tabular}

The test result variable(s): Middle cerebral RI, Middle cerebral $\mathrm{PI}$ has at least one tie between the positive actual state group and the negative actual state group.

At 1.27 uterine artery PI cutoff, sensitivity is $88 \%$ and specificity is $74 \%$. Case1 IUGR
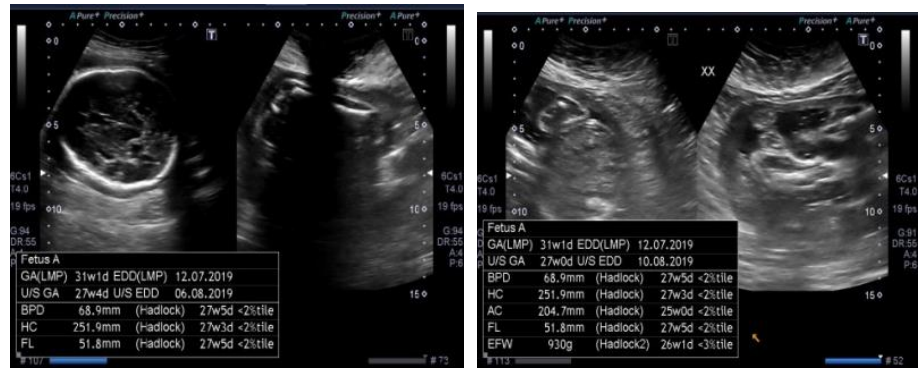

Case 1 hypotrophic fetus. Image (A, B) shows fetus at 27 weeks 5 days of pregnancy. Biometry showed BPD corresponding to 27 weeks 5 DAYS. Fetal weight below $10^{\text {th }}$ percentile. A.C lagginging behind 2 weeks 5 DAYS behind BPD

Case 1: Image $(C, D, E)$ of the same fetus at 27 weeks 5 days showing uterine artery with persistent post systolic notch having R.I, 0.69 and P.I 1.47, high resistant flow.
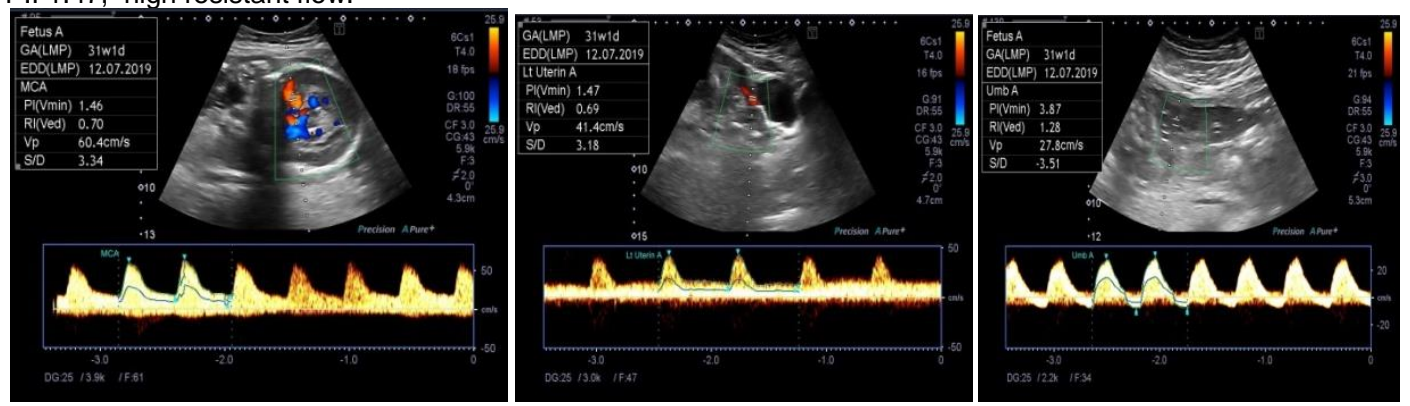

In Image E, umbilical artery showing reversal flow with S.D -3.51 and P.I 3.87, indicative of fetal distress. Image E is of middle cerebral artery which shows R.I 0.70 \& P.I 1.46 with brain sparing phenomenon. 


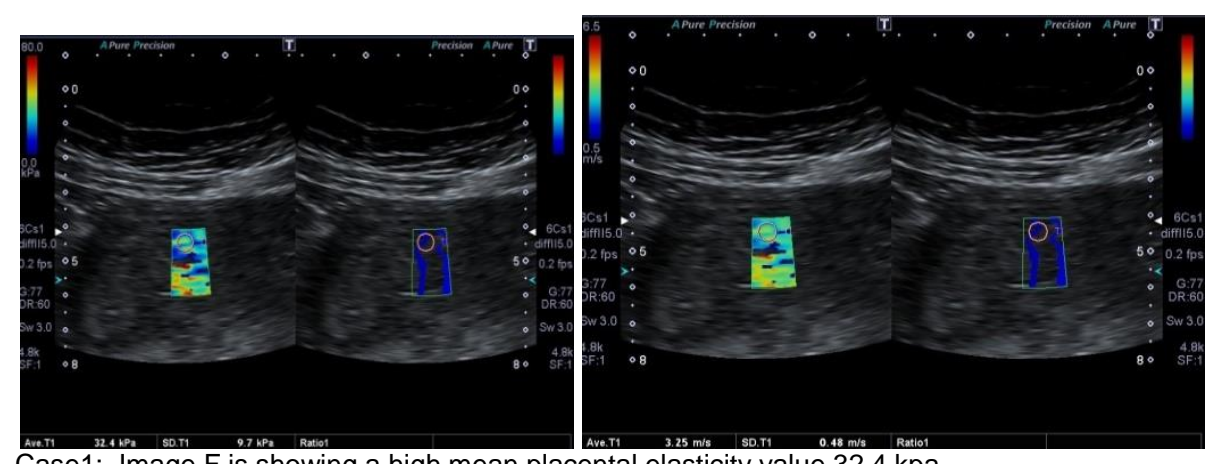

Case1: Image $\mathrm{F}$ is showing a high mean placental elasticity value $32.4 \mathrm{kpa}$

\section{Case 2 of NORMAL fetus}
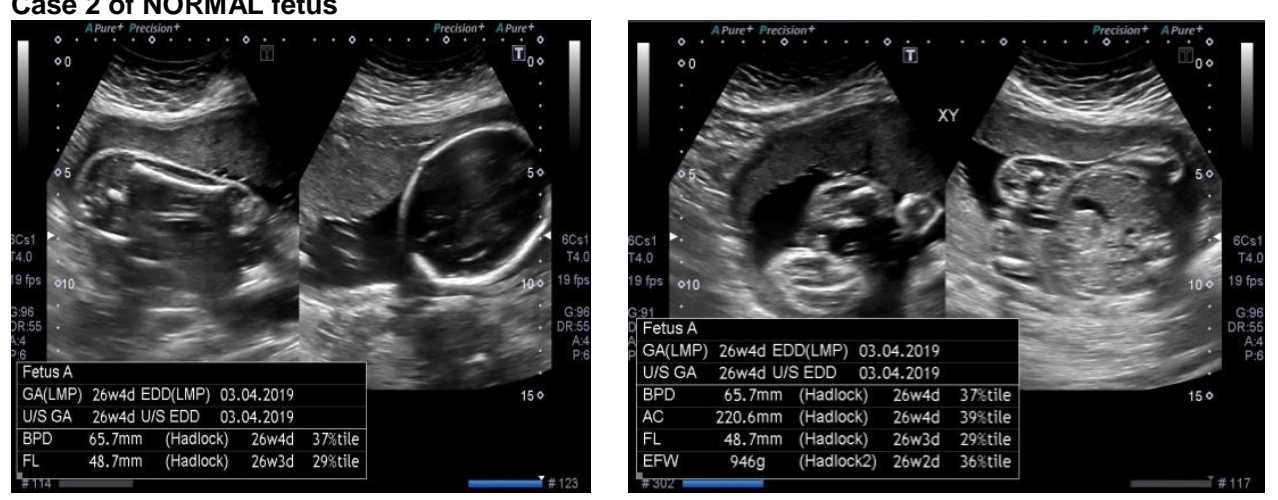

Case 2 normal fetus: Images A,B showing normal biometric values at 26 weeks 4 days.

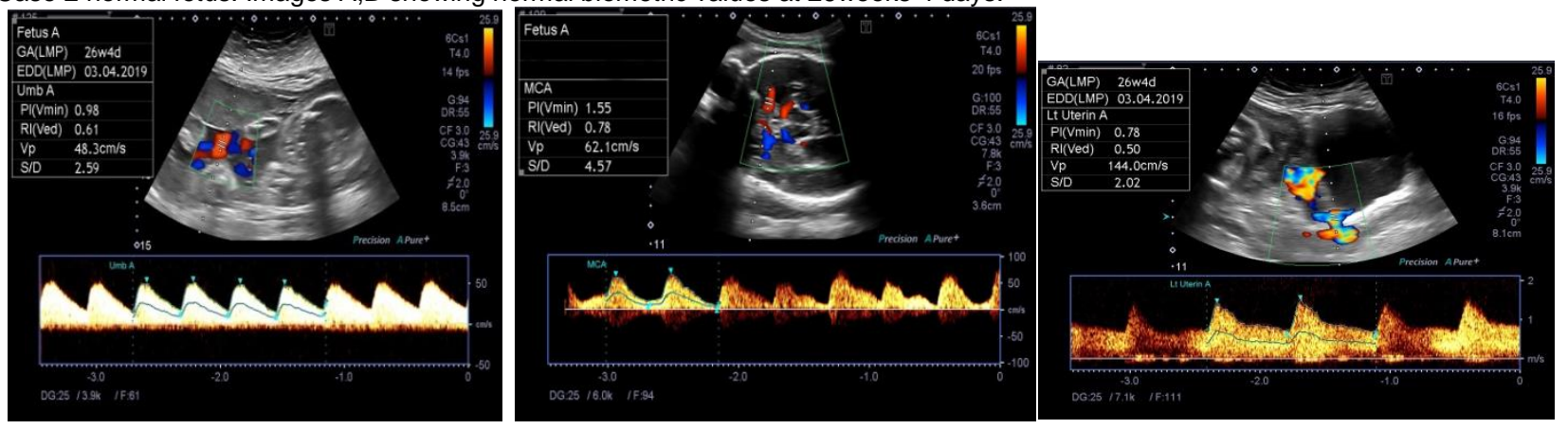

Case 1: Image (C, D, E) of the same fetus at 26 weeks 4 days showing uterine artery with normal forward diastolic flow, having R.I, 0.50 and P.I 0.78. , umbilical artery showing S.D 2.59 and P.I 0.78, M.C.A showing R.I 0.78 and P.I, 1.55inficative of normal indices.

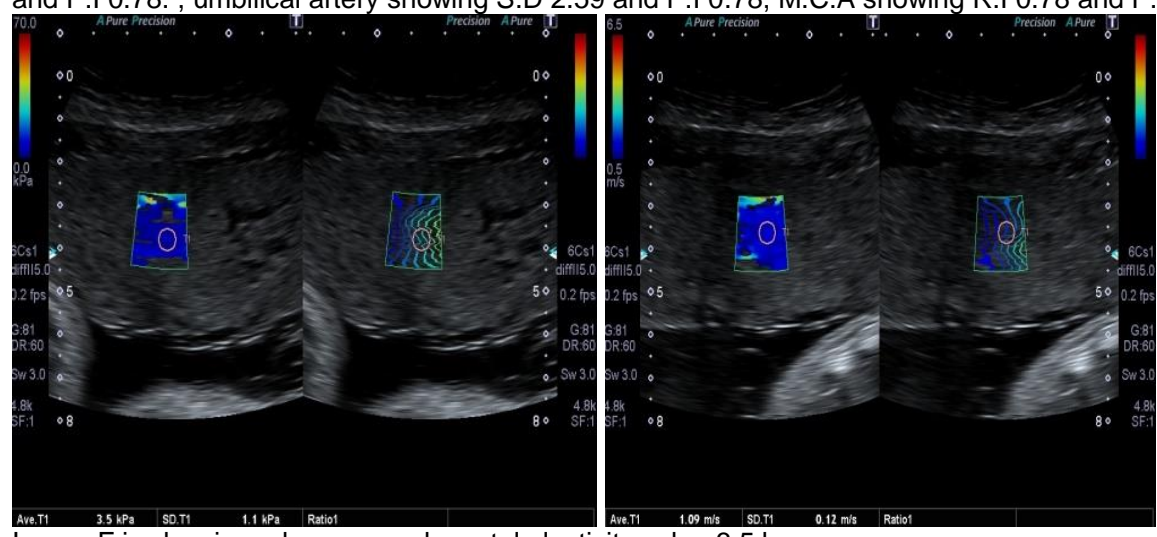

Image $\mathrm{F}$ is showing a low mean placental elasticity value $3.5 \mathrm{kpa}$. 


\section{DISCUSSION}

The placenta, as a vector for the maternal-fetal nutrient and oxygen exchange, is a main influence on the birth weight Placental tissue has fast growth as well as differentiation offering communication between fetus and mother. It contains fetal and maternal components ${ }^{16}$. Color Elastography has capability to evaluate the soft tissue hardness non-invasively ${ }^{17}$. Assessment of placental functioning and morphology is important antenatally because of onus it has on the growth of fetus. Tissue elasticity assessment can provide quantitative data regarding its functioning ${ }^{18}$. There are limited studies available regarding placental elasticity. A study conducted by Sugitani and colleagues utilizing ARFI elastography reported that elevated values of SWV during pregnancies culminate the growth retarded fetuse ${ }^{19}$. In a study Yamanka and coworkers established positive association between fetal growth and placental stiffness ${ }^{20}$ Habibi et $\mathrm{al}^{21}$.

Durhan $^{22}$ et al described stiffer placentas during IUGR pregnancies. Fujita ${ }^{23} \mathrm{Y}$ et al. evaluated placental elasticity during pregnancy using PSW elastography and found that the placentas of HDP participants had higher SWV than the placentas of normal individuals. Similar outcomes have been achieved by other groups. Simon and colleagues discovered that preeclampsia patients have much increased placental stiffness, and that placenta elasticity has a strong link with Doppler indices of the uterine, umbilical, and middle cerebral arteries. In recent years, imaging techniques based on elastography have received a lot of attention for non-invasive examination of tissue mechanical characteristics ${ }^{24}$. The tissue stiffness response after application of mechanical force is measured in dedicated imaging modes ${ }^{25}$.

The current study was carried out at Sabiry Color Doppler Ultrasound Centre, Faisalabad to assess the placental elasticity by shear wave elastography versus Doppler studies of hypotrophic fetuses from 24 to 36 weeks of gestation and to determine the diagnostic accuracy of placental elasticity assessment in early detection of hypotrophic fetuses. To acquire appropriate outcome 300 patients were divided into two groups. When maternal age was compared between the two groups, the study documented that the average age of females in the IUGR group was $30.93+4.40$ years, whereas the average age of normal females was 25.034.10 years, and the difference was statistically significant ( $P$ 0.001). According to the findings of a recent study conducted by Khanal ${ }^{26}$ and colleagues, the average age of patients was 25.21 years, whereas the average age of normal females was 24.91 years. The findings were determined to be statistically insignificant $(\mathrm{P}=0.747)$.

In 2016, Alan 27 and colleagues found significant findings $(P=0.05)$. They reported that mean age of cases was $26.8+6.7$ years and among normal females the mean age was $30.0+6.7$ years. It was found during study that in IUGR group, the mean gestational age was $30.24 \pm 2.75$ weeks and among normal females it was $32.41 \pm 2.82$ weeks. The result was found statistically significant ( $P$ $<0.001)$. A similar study carried out by $\mathrm{Cimsit}^{28}$ and collaborators reported that the mean gestational age among IUGR group was $22.0 \pm 3.0$ weeks and among normal females it was $23.0 \pm 2.0$ weeks. Study disclosed that in IUGR group the mean uterine artery RI was $0.70 \pm 0.08$ while among normal females was $0.42 \pm 0.05$ and the outcome was determined to be statistically significant. ( $P=<0.001)$. Our findings are superior to those of Alan's research ${ }^{27}$ and associates who reported statistically insignificant result $(P=0.12)$. They asserted that mean uterine artery $\mathrm{RI}$ in cases was $0.64 \pm 0.2$ and in controls was $0.56 \pm 0.1$. But the results of a most recent study carried out by Hefeda and Zakaria in 2020 exhibited similar scenario that $P$ values was $<0.01$ (statistically significant) while in IUGR group the mean uterine artery $\mathrm{RI}$ was $0.87 \pm 0.11$ and among normal females it was $0.71 \pm 0.45^{29}$.

Evaluation of umbilical artery is utilized as a method to segregate the small fetuses with anomalous placentas from small fetuses with healthful placentas ${ }^{30}$. But the findings of a study undertaken by Hefeda ${ }^{29}$ and Zakaria are comparable with our study results who reported statistically significant results $(P=0.05)$. They confirmed that mean umbilical artery $\mathrm{PI}$ in IUGR group was $2.7 \pm 0.87$ and in normal females it was $1.56 \pm 0.34$. To identify fetal blood flow, fetal MCA Doppler is utilized caused by its better accessibility and elevated reproducibility. The values of MCA RI and PI change during normal gestation. The results of our study indicated that mean middle cerebral $\mathrm{RI}$ was $0.62 \pm 0.05$ in IUGR group while $0.74 \pm 0.05$ in normal group with statistically significant results $(P<0.001)$. Study further disclosed that mean middle cerebral PI in IUGR group was $1.15 \pm 0.26$ and among normal females was $1.63 \pm 0.36$. The findings were determined to be significant statistically ( $P$ 0.001). Virtually the results of our study are comparable with a study undertaken by Sharbaf ${ }^{31}$ and partners in 2018 who asserted that mean middle cerebral $\mathrm{PI}$ in IUGR group was $1.405 \pm 0.377$ and among normal females was $1.799 \pm 0.412$ while the results were found statistically significant $(P<0.000)$.

A related study conducted by Habibi and Assistants ${ }^{20}$ in 2017 showed that all locations in the IUGR group had ominously greater median stiffness values than the control group. The IUGR group had median shear wave values of $28 \mathrm{kPa}$ and $21.5 \mathrm{kPa}$ for the central and peripheral maternal surfaces of the placenta, respectively; the control group had $6 \mathrm{kPa}$ and $5.35 \mathrm{kPa}$ (P 0.001). The IUGR group's central and peripheral foetal placenta shear wave values were 22 and $22.5 \mathrm{kPa}$, respectively, while the control group's values were 5 and $5.30 \mathrm{kPa}$ (P0.001). which are closely correlated with the results of our analysis. Another study published in 2018 by Spiliopoulos 32 and colleagues found that the acute PE group (mean 24.3+4.59 $\mathrm{kPa}$ ) and non-acute PE group (mean $28.0+2.78 \mathrm{kPa}$ ) had pointedly higher placental stiffness than the control group (mean $10.9+1.75 \mathrm{kPa}$ ) due to GAs (p0.05).

In 2015, KIç33 and colleagues discovered a substantial relationship between right uterine artery $\mathrm{PI}$, left uterine artery $\mathrm{PI}$, right uterine artery $\mathrm{RI}$, and left uterine artery $\mathrm{RI}$, with $\mathrm{r}=0.512$, $\mathrm{p}$-value $0.000, r=0.436$, $\mathrm{p}$-value $0.002, r=0.295$, $p$-value 0.038 , and $r=0.339$, p-value 0.016 , respectively. The $\mathrm{RI}$ of the uterine artery is 1.000 , the $\mathrm{PI}$ of 
the uterine artery is 0.993 , the $S / D$ of the umbilical artery is 0.761 , and the $\mathrm{PI}$ of the umbilical artery is 0.909. Test outcome variables At 0.55 , the cut off value of uterine artery $\mathrm{RI}$ with sensitivity was $100 \%$ and $99.3 \%$ specificity . At 1.1 of the uterine artery, the cut off value of $\mathrm{PI}$ with sensitivity was $100 \%$ and $89.3 \%$ specificity. At 3.1 of S/D, the cut off value of the umbilical artery with sensitivity was $94 \%$ and $71 \%$ specificity. The cut off value of the value of placental elasticity was $15 \mathrm{kpa}$ with $100 \%$ sensitivity and $100 \%$ specificity. Middle cerebral artery $\mathrm{RI}=0.66$ with $86 \%$ sensitivity and $76 \%$ specificity. The Middle Cerebral Artery PI was 1.27 , with $88 \%$ sensitivity and $74 \%$ specificity. According to $\mathrm{Li}$ and associates (2012), the best significant mean stiffness value for diagnosing preeclampsia was 7.35 $\mathrm{kPa}$, which had $90 \%$ sensitivity and $86 \%$ specificity. The stable control group had no diastolic notches and had a precision of $100 \%$. The existence of a diastolic notch in the patient population resulted in a sensitivity of $56.5 \%$. In a separate investigation, utilising a $7.35 \mathrm{kPa}$ cutoff value with diastolic notch, sensitivity, specificity, PPV, and NPV rates of $91.3 \%, 92.6 \%, 91.3 \%$ and $92.6 \%$, respectively, were reported. The findings of our research are consistent with a study performed by Li and colleagues ${ }^{34}$.

From a biochemical and histological viewpoint, histopathological structure can only be studied using ex vivo methods. In vivo testing is not possible due to placental fragility during tissue sampling. Imaging techniques are routinely utilised to study placental anatomy and function. Traditional B-mode US can provide information on the placenta's overall appearance and position, but not on its features. Doppler US imaging is a well-known and commonly utilised imaging technique. The method looks for diastolic notches and a PI increase in the uterine arteries in pregnancies that are thought to be at risk of developing preeclampsia in the second trimester ${ }^{35}$. A crucial touchstone is the subject of protection.. During pregnancy, pregnant females undergo repeated US exams. For several years, diagnostic ultrasound has been commonly used in clinical medicine with no proven adverse effects $^{36}$. The elastography system's acoustic performance, mechanical, and thermal indices in this investigation are all within the required safety levels. Sugitani et al investigated the biological effects of acoustic radiation force impulse imaging on full-term placentas, and found no thermal or mechanical structural abnormalities..

Tabaru et $\mathrm{al}^{38}$ evaluated the thermal effect of acoustic radiation force elastography and found that US high intensity could be used for fetal inspection because amnion liquid has no ultrasonic attenuation and does not transmit push waves. We desired to employ elastography for as little time as feasible, especially for superficial placenta imaging. There are multiple limitations to our analysis. In various stages of preeclampsia or complications, we could not assess the diagnostic efficacy of the procedure. Another drawback of our research is the lack of placental histopathological assessment. Histopathological investigation can reveal a link between structural alterations in the anatomy and elastography resultsAlthough the elastography technique was sufficiently standardised, we did not analyse interobserver variability because our goal was to eliminate repeated exams of the same foetus. The randomised inclusion of patients in the research sequence resulted in a slight difference in gestation age between the control and preeclampsia groups. There is no evidence of a link between placenta elasticity and gestational age in the literature. More correlative placenta research are required in order to identify the flexibility of the placenta in relation to gestational age. Finally, we've demonstrated how SWE imaging can be used to diagnose preeclampsia. Real-time demonstrations of elasticity changes can indirectly disclose structural deterioration before the clinical presentation of preeclampsia illness. In our research, we discovered that SWE imaging can be used to predict hypotrophic fetuses.

\section{CONCLUSION}

Study concluded that shear wave elastography is an effective non-invasive technique for the assessment of placental elasticity and can easily identify the hypotrophic fetus in a single step with more accuracy that can be missed on Doppler findings. Further studies are needed on large scale to assess the placental elasticity by shear wave elastography versus Doppler studies of hypotrophic fetuses.

Conflict of interest: Nil

\section{REFERENCE}

1. Sigrist RMS, Liau J, Kaffas AE, Chammas MC, Willmann JK. Ultrasound elastography: review of techniques and clinical applications. Theranostics. 2017; 7(5): 1303-29.

2. Tack J, Munaut C, Blacher S, Noël A, Nisolle M, Chantraine F. Abnormal vascular architecture at the placental-maternal interface in preeclampsia. Why male modern contraception? 2019: 42

3. Devisme L, Merlot B, Ego A, Houfflin-Debarge V, Deruelle P, Subtil D. A case-control study of placental lesions associated with pre-eclampsia. International journal of gynecology \& obstetrics. 2013; 120(2): 165-8.

4. Hirashima C, Ohkuchi A, Nagayama S, Suzuki H, Takahashi K, Ogoyama M, Takahashi H, Shirasuna K, Matsubara S. Galectin-1 as a novel risk factor for both gestational hypertension and preeclampsia, specifially its expression at a low level in the second trimester and a high level after onset. Hypertension research. 2018; 41(1): 45-52.

5. Taljanovic MS, Gimber LH, Becker GW, Latt LD, Klauser AS, Melville DM, Gao L, Witte RS. Shear-wave elastography: basic physics and musculoskeletal applications. Radiographics. 2017 May 11;37(3):855-70.

6. Albouy-Llaty M, Thiebaugeorges O, Goua V. EDEN MotherChild Cohort Study Group. Influence of fetal and parental factors on intrauterine growth measurements: results of the EDEN mother-child.

7. Ottaviani G. Defining sudden infant death and sudden intrauterine unexpected death syndromes with regard to anatomo-pathological examination. Frontiers in Pediatrics. 2016 Sep 21;4:103.

8. Yashima $\mathrm{Y}$, Sasahira $\mathrm{N}$, Isayama $\mathrm{H}$, et al. Acoustic radiation force impulse elastography for noninvasive assessment of chronic pancreatitis. J Gastroenterol 2012; 47:427-432.

9. Arda K, Ciledag N, Gumusdag P. Differential diagnosis of malignant cervical lymph nodes at real-time ultrasonographic elastography and Doppler ultrasonography. Hungarian Radiol Online2010; 6:12-15.

10. Friedrich-Rust M, Nierhoff $\mathrm{J}$, Lupsor M, et al. Performance of acoustic radiation force impulse imaging for the staging of liver fibrosis: a pooled meta-analysis. J Viral Hepat2012; 19:e212-e219. 
11. Marcy PY, Thariat J, Lacout A. Should we catch the train of shear-wave elastography? AJR Am J Roentgenol2012; 198:W624-W625.

12. Athanasiou A, Tardivon A, Tanter M, et al. Breast lesions: quantitative elastography with supersonic shear imagingpreliminary results. Radiology2010; 256:297-303.

13. Murphy DJ, Striate GM. Mortality and morbidity associated with earlyonset preeclampsia.Hypertens Pregnancy 2000; 19:221-231.

14. Papageorghiou AT, Yu CK, Nicolaides KH. The role of uterine artery Doppler in predicting adverse pregnancy outcome. Best Pract Res Clin Obstet Gynaecol 2004; 18:383-396.

15. Yu CK, Khouri O, Onwudiwe N, Spiliopoulos Y, Nicolaides $\mathrm{KH}$; Fetal Medicine Foundation Second-Trimester Screening Group. Prediction of pre-eclampsia by uterine artery Doppler imaging: relationship to gestational age at delivery and smallfor-gestational age. Ultrasound Obstet Gynecol 2008; 31:310-313.

16. Kiran N, Aslam N, Tabassum T, Kanwal S, Zia T. Morphological findings in intrauterine growth restriction (IUGR) placentas versus normal placentas in pregnant women of district Rawalpindi, Pakistan. Gomal journal of medical sciences. 2019; 17(3): 65-9.

17. Aggarwal A, Mehra R, Sharma A. Role of ARFI elastography in assessment of differences in quantitative placental elasticity in normal versus intra uterine growth retarded pregnancies. International journal of medical research professionals. 2018; 4(1): 449-52.

18. Mashiane SE. Ultrasound biosafety: knowledge and practices of health practitioners who perform obstetric scans in SA (Doctoral dissertation, University of Johannesburg).

19. Sugitani M, Fujita Y, Yumoto Y, Fukushima K, Takeuchi T, Shimokawa M, et al. A new method for measurement of placental elasticity: acoustic radiation force impulse imaging. Placenta. 2013; 34: 1009-13.

20. Yamanka Z, Hassegawa T, Kuji N, Natori M, Notake H, Sasaki T, et al. Relationship between fetal growth restriction and elasticity of placental tissue evaluated by ultrasound. Placenta. 2016; 46: 104-5.

21. Habibi HA, Davutoglu EA, Kandemirli SG, Aslan M, Ozel A, Ucar AK, et al. In vivo assessment of placental elasticity in intrauterine growth restriction by shear-wave elastography. European journal of radiology. 2017; 97: 16-20.

22. Durhan G, Ünverdi H, Deveci C, Büyükşireci M, Karakaya J, Değirmenci $\mathrm{T}$, et al. Placental elasticity and histopathological findings in normal and intra-uterine growth restriction pregnancies assessed with strain elastography in ex vivo placenta. Ultrasound in medicine and biology. 2017; 43(1): 111-8.

23. Fujita Y, Nakanishi TO, Sugitani M, Kato K. Placental Elasticity as a New Non-invasive Predictive Marker of Preeclampsia. Ultrasound in medicine \& biology. 2019 Jan 1;45(1):93-7.

24. Simon EG, Callé S, Perrotin F, Remenieras JP. Measurement of shear wave speed dispersion in the placenta by transient elastography: a preliminary ex vivo study. PloS one. 2018; 13(4): e0194309.
25. Yeoh HJ, Kim TY, Ryu JA. The feasibility of shear wave elastography for diagnosing superficial benign soft tissue masses. Ultrasonography. 2019; 38(1): 37.

26. Khanal UP, Chaudhary RK, Ghanshyam G. Placental elastography in intrauterine growth restriction: a case-control study. Journal of clinical research in radiology. 2019; 2(2): 17.

27. Alan B, Göya C, Tunç S, Teke M, Hattapoglu S. Assessment of placental stiffness using acoustic radiation force impulse elastography in pregnant women with fetal anomalies. The Korean society of radiology. 2016; 17(2): 218-23.

28. Cimsit C, Yoldemir T, Akpinar IN. Shear wave elastography in placental dysfunction: comparison of elasticity values in normal and preeclamptic pregnancies in the second trimester. Journal of ultrasound in medicine. 2015; 34: 151-9.

29. Hefeda MM, Zakaria A. Shear wave velocity by quantitative acoustic radiation force impulse in the placenta of normal and high-risk pregnancy. Egyptian journal of radiology and nuclear medicine. 2020; 51: 131 .

30. Dicke JM, Huettner P, Odibo SYA, Kraus FT. Umbilical artery doppler indices in small for gestational age fetuses. Journal of ultrasound in medicine. 2009; 28(12): 1603-10.

31. Sharbaf FR, Movahed F, Pirjani R, Teimoory N, Shariat M, Farahani Z. Comparison of fetal middle cerebral artery versus umbilical artery color Doppler ultrasound for predicting neonatal outcome in complicated pregnancies with fetal growth restriction. Biomedical research and therapy. 2018; 5(5): 2296-2304.

32. Spiliopoulos M, Kuo CY, Eranki A, lqbal S, Fisher JP, Fries $M$, et al. Determining in-vivo placental stiffness in healthy and preeclamptic pregnancies using shear-wave elastography. American journal of obstetrics and gynecology. 2018; 467: S281.

33. Kılıç F, Kayadibi Y, Yüksel MA, Adaletli I, Ustabaşıoğlu FE, Öncül $M$, et al. Shear wave elastography of placenta: in vivo quantitation of placental elasticity in preeclampsia. Diagnostic and interventional radiology. 2015; 21: 202-7.

34. Li W, Wei Z, Yan R, Zhang Y. Detection of placenta elasticity modulus by quantitative real-time shear wave imaging. Clinical and experimental obstetrics and gynecology. 2012; 39(4): 470-3.

35. Espinoza J, Kusanovic JP, Bahado-Singh R, et al. Should bilateral uterine artery notching be used in the risk assessment for preeclampsia, small-for-gestational-age, and gestational hypertension? J Ultrasound Med 2010; 29:11031115.

36. Kollmann C, Jenderka KV, Moran CM, Draghi F, Diaz JJ, Sande R. EFSUMB Clinical Safety Statement for Diagnostic Ultrasound-(2019 revision). Ultraschall in der MedizinEuropean Journal of Ultrasound. 2020 Aug;41(04):387-9.

37. Dekker G, Sibai B. Primary, secondary, and tertiary prevention of pre-eclampsia. Lancet 2001; 357:209-215

38. Tabaru M, Yoshikawa H, Azuma T, Asami R, Hashiba K. Experimental study on temperature rise of acoustic radiation force elastography. J Med Ultrasonics 2012; 39:137-146. 